\title{
La ciudadanía del Mercosur: desafíos para su implementación
}

\author{
María Alejandra Perícola
}

\section{Introducción}

En la medida en que persiste el dualismo ciudadaníanacionalidad, el único de los derechos fundamentales que se mantiene reservado a los nacionales es el derecho de sufragio y, salvo en elecciones municipales, se excluye a los extranjeros de la formación del gobierno representativo. Partiendo de esta premisa, el objetivo de este trabajo es observar el estado de situación del derecho de sufragio de los extranjeros en el ámbito del Mercado Común del Sur (Mercosur) ${ }^{2}$ en pos de la implementación de una ciudadanía regional.

En principio, se analizan los estándares internacionales en torno a los derechos de participación política y la integración de los extranjeros y se presenta una apostilla sobre los conceptos de nacionalidad, ciudadanía y extranjería.

Luego, en el ámbito del Derecho comparado, se consideran los casos de países que admiten el derecho de sufragio activo y pasivo en las elecciones locales únicamente a los ciudadanos de la Unión Europea; aquellos que establecen el criterio de

\footnotetext{
1 Abogada y Licenciada en Ciencia Política. Máster en Derecho Electoral, Universidad de Castilla-La Mancha, Toledo, España. Profesora de Teoría del Estado, Derecho Constitucional y Principios Generales del Derecho Latinoamericano en la Universidad de Buenos Aires. mpericola@derecho.uba.ar.

2 El Mercosur se conformó el 26 de marzo de 1991 mediante la suscripción del Tratado de Asunción por la República Argentina, la República Federativa de Brasil, la República del Paraguay y la República Oriental del Uruguay. El 4 de julio de 2006 se aprobó el "Protocolo de Adhesión de la República Bolivariana de Venezuela al Mercosur", por el cual Venezuela fue el primer país en sumarse como Estado Parte. Bolivia se encuentra en proceso de adhesión. El Mercosur tiene como Estados Asociados a la República de Chile, la República de Colombia, la República del Ecuador, la República Cooperativa de Guyana, la República de Perú y la República de Surinam.
} 
reciprocidad como condición para otorgar el derecho de sufragio a los extranjeros; países que admiten el derecho de sufragio a los extranjeros en las elecciones locales; y aquellos que reservan el derecho de sufragio a los nacionales en todo tipo de elecciones.

Por último, el planteo de los desafíos para la implementación de una ciudadanía del Mercosur requiere analizar los regímenes de extranjería de los Estados Partes del bloque regional.

\section{Los estándares internacionales en torno a los derechos de participación política y la integración de los extranjeros}

Con el objetivo de promover la democracia y fortalecer el Estado de derecho, desde mediados del siglo XX una serie de instrumentos internacionales de derechos humanos han conferido una base jurídica a los derechos a la participación política. En el sistema interamericano, el artículo 23, apartado 1, de la Convención Americana sobre Derechos Humanos ${ }^{3}$ consagra el derecho de los ciudadanos a votar y ser elegidos en elecciones periódicas auténticas, realizadas por sufragio universal, igual y secreto; esto último, con el fin de garantizar la libre expresión de la voluntad de los electores. Asimismo, en su artículo 3, la Carta Democrática Interamericana ${ }^{4}$ ha dispuesto lo siguiente:

Son elementos esenciales de la democracia representativa, entre otros, el respeto a los derechos humanos y las libertades fundamentales; el acceso al poder y su ejercicio con sujeción al Estado de derecho; la celebración de elecciones periódicas, libres, justas y basadas en el sufragio universal y secreto como expresión de la soberanía del pueblo; el régimen plural de partidos y

\footnotetext{
3 Suscripta en San José, Costa Rica, el 22 de noviembre de 1969.

4 Aprobada en la primera sesión plenaria de la Asamblea General de la Organización de los Estados Americanos, celebrada en Lima, Perú, el 11 de septiembre de 2001 durante el vigésimo octavo período de sesiones.
} 
organizaciones políticas; y la separación e independencia de los poderes públicos.

En el sistema de Naciones Unidas, el derecho de participación política se contempla en tres instrumentos: 1) el artículo 21.1 de la Declaración Universal de los Derechos Humanos ${ }^{5}$; 2) en el artículo 25 del Pacto Internacional de Derechos Civiles y Políticos $^{6}$-que no incluye posibles causales para la restricción o reglamentación de los derechos políticos (que sí se incluyen en el art. 23.2 de la CADH), aunque establece que éstos no pueden ser limitados por restricciones indebidas-; y 3) en el artículo 5 c) de la Convención Internacional sobre la Eliminación de todas las Formas de Discriminación Racial. ${ }^{7}$

En el seno de la Organización Internacional para las Migraciones, en 1990 se adoptó la Convención Internacional para la Protección de todos los Trabajadores Migratorios y de sus Familiares $^{8}$, que en el artículo 41 establece:

1. Los trabajadores migratorios y sus familiares tendrán derecho a participar en los asuntos públicos de su Estado de origen y a votar y ser elegidos en elecciones celebradas en ese Estado, de conformidad con su legislación.

2. Los Estados de que se trate facilitarán, según corresponda y de conformidad con su legislación, el ejercicio de esos derechos.

A continuación, el artículo 42 dispone lo siguiente:

1. Los Estados de empleo facilitarán, de conformidad con su legislación nacional, la consulta o la participación de los trabajadores migratorios y sus familiares en las decisiones relativas a la vida y la administración de las comunidades locales.

\footnotetext{
5 Aprobada y proclamada por la Asamblea General de las Naciones Unidas en París el 10 de diciembre de 1948.

6 Suscripto en New York, Estados Unidos de América, el 19 de diciembre de 1966.

7 Suscripta en New York, Estados Unidos de América, el 13 de julio de 1967.

8 Entrada en vigor el 1 de julio de 2003.
} 
2. Los trabajadores migratorios podrán disfrutar de derechos políticos en el Estado de empleo si ese Estado, en el ejercicio de su soberanía, les concede tales derechos.

En el marco del Consejo de Europa, el Convenio Europeo de Derechos Humanos (CEDH), en el artículo 3 del Protocolo Adicional $^{9}$, no reconoce como tal el derecho de sufragio, sino la obligación de los Estados de “... organizar, a intervalos regulares, elecciones libres con escrutinio secreto, en condiciones que garanticen la libre expresión de la opinión del pueblo en la elección del cuerpo legislativo". Sin embargo, en la actualidad esta deficiente regulación ha sido paliada, al menos en parte, a partir del Protocolo $\mathrm{n}^{\mathrm{o}}$ 12, adoptado por el Comité de Ministros en Roma el 26 de junio de 2000, relativo al principio de igualdad, que permite conocer al Tribunal Europeo de cualquier violación de la igualdad en relación con cualquier derecho, con independencia de su reconocimiento o no en el CEDH o en la ley. ${ }^{10}$

El Convenio Europeo sobre la Participación de los Extranjeros en la Vida Pública a Nivel Local ${ }^{11}$ dispone que cada Estado Parte se compromete a reconocer el derecho de los extranjeros, con residencia legal y habitual durante cinco años, a ser electores y elegibles en las elecciones locales, con los mismos requisitos exigidos a los nacionales (art. 6.1). A esto se agrega la autorización a los Estados para declarar, en el momento de la ratificación, que el derecho se extenderá exclusivamente al sufragio activo, no a la posibilidad de ser elegido para los cargos locales (art. 6.2).

Por su parte, la integración política de los inmigrantes mediante el derecho de sufragio en el Derecho Comunitario

\footnotetext{
9 Firmado en París el 20 de marzo de 1952.

10 Rebato Peño, M. E., Análisis comparado México-España de los derechos político-electorales, México, Tribunal Electoral del Poder Judicial de la Federación, 2010, p. 22.

11 Entró en vigor el 1 de mayo de 1997. Fue firmado por trece Estados y ratificado por Albania, Dinamarca, Finlandia, Islandia, Italia, Lituania, Países Bajos, Noruega y Suecia. Datos aportados en Tomé da Mata, E., "Participación de los ciudadanos de la Unión Europea en las elecciones al Parlamento Europeo y elecciones locales en España", Revista de Investigaciones Políticas y Sociológicas, Vol. 14, núm. 1, 2015, p. 41.
} 
se ha realizado a través del Tratado de la Unión Europea ${ }^{12}$, que crea su propia ciudadanía y otorga a todo ciudadano que resida en un Estado miembro del que no sea nacional el derecho a ser elector y elegible en las elecciones municipales y en las del Parlamento Europeo, en las mismas condiciones que los nacionales de dicho Estado.

Mediante la directiva 93/109/CE ${ }^{13}$ del Consejo de la Unión Europea se regularon “... las modalidades del ejercicio del derecho de sufragio activo y pasivo en las elecciones al Parlamento Europeo para los ciudadanos de la Unión que residan en un Estado miembro del que no son nacionales". En ellas se disponen los requisitos para ejercer el derecho de sufragio activo y pasivo: ser ciudadano de la Unión; residir en el Estado miembro y cumplir las mismas condiciones exigidas a los nacionales del país de residencia; la prohibición de doble voto (la posibilidad de elegir para sufragar el Estado de la nacionalidad o el de la residencia); la inscripción previa en el censo electoral; y el reconocimiento de disposiciones transitorias excepcionales aplicables a cualquier país en el que la proporción de ciudadanos nacionales de otros Estados miembros residentes en su territorio y en edad de votar superase el veinte por ciento del electorado. ${ }^{14}$

Asimismo, el noveno de los "Principios básicos comunes para la política de integración de los inmigrantes en la Unión Europea" acordados por el Consejo de la Unión Europea ${ }^{15}$, señala:

La participación de los inmigrantes en el proceso democrático y en la formulación de las políticas y medidas de integración, especialmente a nivel local, favorece su integración. Permitir que los inmigrantes tengan voz en

\footnotetext{
12 Firmado en Maastricht el 7 de diciembre de 1992.

13 Fechada el 6 de diciembre de 1993.

14 Durán Muñoz, R. y Martín Martínez, M., La integración política de los inmigrantes, Granada, Comares, 2008, p. 126.
}

15 Sesión N² 2618 del Consejo. Bruselas, 19 de noviembre de 2004. 
la formulación de políticas que les afecten directamente puede dar como resultado una política de mayor utilidad para los inmigrantes que aumente su sentido de pertenencia. Siempre que sea posible, los inmigrantes deben participar en todos los aspectos del proceso democrático. La manera de alcanzar esta participación y generar un entendimiento mutuo podría alcanzarse mediante un diálogo estructurado entre los grupos de inmigrantes y los gobiernos. Siempre que fuera posible, los inmigrantes podrían incluso participar en las elecciones, gozar del derecho a votar y afiliarse a partidos políticos.

Por último, el artículo 9 de la versión consolidada del Tratado de la Unión Europea, resultado de las modificaciones introducidas por el Tratado de Lisboa firmado el 13 de diciembre de 2007 y que entró en vigor el 1 de diciembre de 2009, dispone lo siguiente:

La Unión respetará en todas sus actividades el principio de la igualdad de sus ciudadanos, que se beneficiarán por igual de la atención de sus instituciones, órganos y organismos. Será ciudadano de la Unión toda persona que tenga la nacionalidad de un Estado miembro. La ciudadanía de la Unión se añade a la ciudadanía nacional sin sustituirla.

Esta ojeada de los instrumentos internacionales nos permite arribar a una primera reflexión respecto de nuestro objeto de estudio referido al estado de situación de los derechos de participación política y la integración de los extranjeros. Mientras que en el sistema interamericano el ejercicio de los derechos políticos se vincula con la ciudadanía, en el sistema europeo se identifica expresamente con la posesión de la nacionalidad de un Estado miembro. En este sentido, cabe realizar una breve reseña en torno a estos asuntos, según el derecho internacional.

\section{Nacionalidad, ciudadanía y extranjería}

El derecho a la nacionalidad está reconocido por el derecho internacional. La Corte Interamericana de Derechos Humanos 
(CIDH) ha definido la nacionalidad como "... el vínculo jurídico político que liga a una persona con un Estado determinado por medio del cual se obliga con él con relaciones de lealtad y fidelidad y se hace acreedor a su protección diplomática" ${ }^{16}$. Por ello, “... con distintas modalidades, la mayoría de los Estados han establecido la posibilidad de que personas que no tenían originalmente su nacionalidad puedan adquirirla posteriormente, en general, mediante una declaración de voluntad manifestada previo cumplimiento de ciertas condiciones" ${ }^{\prime 17}$.

La ciudadanía, en cambio, consiste “... en una condición según la cual un individuo pertenece al orden político de una nación y se halla en actitud de ejercer los derechos políticos inherentes a su Constitución"18. En ella se hace referencia al concreto "contenido jurídico participativo que se anuda a la pertenencia" de la persona o individuo a la colectividad humana o comunidad. ${ }^{19}$

Con relación a los extranjeros, cada Estado es soberano para formular las condiciones jurídicas que rigen para ellos en el marco de las normas internacionales que forman su ordenamiento jurídico. Por ejemplo, el artículo 1 de la Convención Relativa a los Derechos de Extranjería, suscripta en México en $1902^{20}$, estableció:

Los extranjeros gozan de todos los derechos civiles de que gozan los nacionales, y deben hacer uso de ellos en el fondo, en la forma o procedimiento y en los recursos a que den lugar, absolutamente en los mismos términos

\footnotetext{
16 CIDH, “Opinión Consultiva OC-4/84 del 11 de enero de 1984. Propuesta de modificación a la Constitución Política de Costa Rica relacionada con la naturalización", Serie A Nº 5.

17 Ídem.

18 González, J. V., Manual de la Constitución Argentina, Buenos Aires, Ángel Estrada y Cía., [1897], decimoquinta edición, s.d., p. 216.

19 Ferreyra, R. G., Fundamentos Constitucionales, Buenos Aires, Ediar, 2ª ed., 2015, p. 369.

20 En el marco de la Segunda Conferencia Internacional Americana. Suscripta por Argentina, Bolivia, Colombia, Costa Rica, Chile, República Dominicana, Ecuador, El Salvador, Estados Unidos de América, Guatemala, Haití, Honduras, México, Nicaragua, Paraguay, Perú y Uruguay.
} 
que dichos nacionales, salvo lo que disponga la Constitución de cada país. ${ }^{21}$

Luego, la Convención sobre Condiciones de los Extranjeros de $1928^{22}$ reafirmó el reconocimiento de los Estados a los extranjeros domiciliados o transeúntes en su territorio de todas las garantías individuales que reconocen a favor de sus propios nacionales, y el goce de los derechos civiles. Sin embargo, se dispuso una clara limitación al ejercicio de los derechos políticos en el artículo 7: "El extranjero no debe inmiscuirse en las actividades políticas privativas de los ciudadanos del país en que se encuentre; si lo hiciere quedará sujeto a las sanciones previstas en la legislación local".

Hoy los derechos civiles de los extranjeros se encuentran consolidados en todos los Estados occidentales, al mismo tiempo que se ha ampliado el concepto de ciudadanía hasta hacerlo converger con la nacionalidad (ningún nacional puede quedar excluido de participar en los asuntos públicos). No obstante ello -y más allá de las elecciones locales o municipales-, el único de los derechos fundamentales que en muchos países no se otorga a los extranjeros y se mantiene reservado a los nacionales es el derecho de sufragio.

Si bien en el ámbito de la Unión Europea se ha superado el dualismo ciudadanía-nacionalidad a través de la definición del "ciudadano europeo" (toda persona que tenga una de las nacionalidades existentes en la Unión), esta superación es parcial. La ciudadanía se otorga exclusivamente en razón de la nacionalidad de alguno de los Estados miembros, y no puede

\footnotetext{
21 La Convención sobre Derechos y Deberes de los Estados, adoptada en Montevideo en 1933, agregó que la jurisdicción de los Estados en los límites del territorio nacional se aplica a todos los habitantes. Los nacionales y extranjeros se hallan bajo la misma protección de la legislación y de las autoridades nacionales, y los extranjeros no podrán pretender derechos diferentes ni más extensos que los de los nacionales (art. 9).

22 Emanada de la Sexta Conferencia Internacional Americana, celebrada en La Habana, Cuba, el 20 de febrero de 1928. Signada por Argentina, Bolivia, Brasil, Chile, Colombia, Costa Rica, Cuba, Ecuador, El Salvador, Estados Unidos, Guatemala, Haití, Honduras, México, Nicaragua, Panamá, Paraguay, Perú, República Dominicana, Uruguay y Venezuela.
} 
adquirirse de forma independiente ${ }^{23}$. Los residentes provenientes de terceros países se encuentran excluidos de la ciudadanía europea.

A partir de estos factores, Aláez Corral ${ }^{24}$ propone desunir los conceptos de "ciudadanía" y "nacionalidad": mientras que la nacionalidad es un concepto externo para delimitar las fronteras personales del Estado hacia el exterior, la ciudadanía tiene que ser considerada un concepto incluyente enlazado al reconocimiento de derechos que permita la máxima integración al mayor número posible de individuos.

\section{EI derecho de sufragio de los extranjeros en el Derecho comparado}

Es preciso partir de la siguiente afirmación del catedrático Santolaya: "todavía no existe ningún país en el mundo que reconozca incondicionalmente el derecho de sufragio activo y pasivo en todo tipo de elecciones a todos los extranjeros que se encuentran en su territorio" 25 . En este sentido, en el Derecho comparado se pueden distinguir cuatro grupos de países: aquellos que autorizan exclusivamente a los ciudadanos de la Unión Europea el ejercicio del derecho de sufragio activo y pasivo en el ámbito local; los que reconocen el derecho de sufragio de los extranjeros en las elecciones municipales atendiendo a criterios de reciprocidad; aquellos que admiten el derecho de sufragio activo a los extranjeros en las elecciones locales; y los que reservan el derecho de sufragio a los nacionales en todo tipo de elecciones.

\footnotetext{
23 Santolaya, P. y Revenga Sánchez, M., Nacionalidad, Extranjería y Derecho de Sufragio, Madrid, Centro de Estudios Políticos y Constitucionales, 2007, p. 27.

24 Aláez Corral, B., Nacionalidad, ciudadanía y democracia, Madrid, Centro de Estudios Políticos y Constitucionales, 2006, p. 205.

25 Santolaya, P. , "Los Acuerdos sobre voto en las elecciones municipales de la IX Legislatura", en Matia Portilla, F. J. (dir.), Pluralidad de ciudadanías, nuevos derechos y participación democrática, Madrid, Centro de Estudios Políticos y Constitucionales, 2011, p. 19.
} 


\section{IV.1. El ejercicio del derecho de sufragio activo y pasivo de los extranjeros en las elecciones municipales de los Estados miembros de la Unión Europea}

Si bien en Irlanda y Gran Bretaña se autoriza el derecho de sufragio de los extranjeros tanto en la faz activa como pasiva en todas las elecciones, también es cierto que tal autorización se refiere a "determinados extranjeros" (en el caso británico, los que provienen de Irlanda y de la Commonwealth). ${ }^{26}$

Alemania, Francia e Italia sólo reconocen la posibilidad de ejercer el derecho de sufragio activo y pasivo en el ámbito municipal a los ciudadanos de la Unión Europea, y a ningún otro extranjero. ${ }^{27}$

En Alemania, la referencia al "pueblo" en la Ley Fundamental de Bonn es exclusiva al pueblo alemán. Así lo ha interpretado el Tribunal Constitucional Federal y la doctrina, por lo que no es posible el reconocimiento del derecho de sufragio a ningún extranjero, con la única excepción de los comunitarios. ${ }^{28} \mathrm{El}$ artículo 28.1 de la Constitución establece lo siguiente:

En los Länder, distritos y municipios, el pueblo debe tener una representación surgida de elecciones generales, directas, libres, iguales y secretas. En los distritos y municipios, de acuerdo con el Derecho de la Comunidad Europea, el derecho de votar y de ser elegido lo tienen también las personas que posean la nacionalidad de un Estado miembro de la Comunidad Europea.

En Francia, el artículo 88.3 de la Constitución ${ }^{29}$ reconoció la participación política de los extranjeros de manera limitada:

Sólo podrá concederse derecho de sufragio activo y pasivo en las elecciones municipales a los ciudadanos

\footnotetext{
26 Cfr. Santolaya, P. y M. Díaz Crego, El sufragio de los extranjeros. Un estudio comparado, Madrid, Centro de Estudios Políticos y Constitucionales, 2008, pp. 38-39.

27 De igual manera, en Austria, Bulgaria, Chipre, Grecia, Letonia, Polonia y Rumania.

28 Santolaya, P. y Díaz Crego, M., El sufragio de los extranjeros. Un estudio comparado, op. cit., p. 54.
}

29 Añadido el 26/6/1992. 
de la Unión residentes en Francia, quienes no podrán ejercer las funciones de alcalde o teniente de alcalde ni participar en la designación de electores senatoriales ni en la elección de senadores.

El artículo 48 de la Constitución italiana dispone que "son electores todos los ciudadanos, hombres y mujeres que han alcanzado la mayoría de edad". La identificación entre ciudadanía y nacionalidad se efectúa en la Ley $N^{\circ} 91$ de Ciudadanía Italiana del 5 de febrero de $1992^{30}$. Las normas que organizan las elecciones para la Cámara de Diputados y el Senado no consideran la extensión del derecho de sufragio a los extranjeros. Tampoco se prevé para las elecciones locales, excepto respecto de los ciudadanos de la Unión Europea.

\section{IV.2. El criterio de reciprocidad como condición para otorgar el derecho de sufragio a los extranjeros}

En España, de conformidad con lo dispuesto en el artículo $13.2^{31}$ en relación con el $23^{32}$ de la Constitución Española (CE), la Ley Orgánica 5/1985 del 19 de junio del Régimen Electoral General (en adelante, LOREG) reserva a los españoles, en principio, el derecho de sufragio activo y pasivo (arts. 2 y 6). Sin embargo, para las elecciones municipales, el artículo 176 dispone que los residentes extranjeros, cuyos respectivos países permitan el voto a los españoles (reciprocidad) en los términos de un Tratado, gozan del derecho de sufragio activo. Agrega, asimismo, que gozan de este derecho los residentes en España que, sin haber adquirido la nacionalidad española, tengan la condición de ciudadanos de la Unión Europea.

\footnotetext{
30 Publicada en la Gazzetta Ufficiale del 15 de febrero de 1992.

31 "Art. 13.2: Solamente los españoles serán titulares de los derechos reconocidos en el art. 23, salvo lo que, atendiendo a criterios de reciprocidad, pueda establecerse por tratado o ley para el derecho de sufragio activo y pasivo en las elecciones municipales".

32 "Art. 23.1: Los ciudadanos tienen el derecho a participar en los asuntos públicos, directamente o por medio de representantes, libremente elegidos en elecciones periódicas por sufragio universal". "Art.23.2: Asimismo, tienen derecho a acceder en condiciones de igualdad a las funciones y cargos públicos, con los requisitos que señalen las leyes".
} 
Respecto del derecho de sufragio pasivo, el artículo 177.1 de la LOREG establece que son elegibles en las elecciones municipales todas las personas residentes en España que, sin haber adquirido la nacionalidad española, tengan la condición de ciudadanos de la Unión Europea, o bien sean nacionales de países que otorguen a los ciudadanos españoles el derecho de sufragio pasivo en sus elecciones municipales en los términos de un Tratado. El marco legal del régimen de extranjería español se completa con la Ley Orgánica 4/2000, del 11 de enero, sobre derechos y libertades de los extranjeros en España y su integración social.

El criterio de reciprocidad a que se refiere el artículo 13.2 de la CE exige dos elementos: que los Estados en cuestión permitan el voto a los españoles y la existencia de un Tratado. Por ello, el reconocimiento del derecho de sufragio a los extranjeros se encuentra muy limitado. ${ }^{33}$

En términos similares, el artículo 15.4 de la Constitución de Portugal establece que, sujeto al principio de reciprocidad, la ley puede otorgar a los extranjeros residentes en el país el derecho a votar y a presentarse como candidato en las elecciones a consejos locales. También de acuerdo al principio de reciprocidad, la ley puede otorgar a los ciudadanos de los Estados miembros de la Unión Europea que residen el Portugal el derecho a votar y a presentarse como candidatos en las elecciones a miembros del Parlamento Europeo (art. 15. 5).

\section{IV.3. Países que admiten el derecho de sufragio a los extranjeros en las elecciones locales}

En la Argentina el artículo 20 de la Constitución Nacional (CN) señala lo siguiente:

\footnotetext{
33 Véase Santolaya, P. , "El derecho de sufragio de los extranjeros en las elecciones municipales", en Rubio Llorente, F. y Biglino Campos, P. , El informe del Consejo de Estado sobre la reforma electoral: Texto del informe y debates académicos, Madrid, Consejo de Estado y Centro de Estudios Políticos y Constitucionales, 2009, p. 31.
} 
Los extranjeros gozan en el territorio de la Nación de todos los derechos civiles del ciudadano; pueden ejercer su industria, comercio y profesión; poseer bienes raíces, comprarlos y enajenarlos; navegar los ríos y costas; ejercer libremente su culto; testar y casarse conforme a las leyes. No están obligados a admitir la ciudadanía, ni a pagar contribuciones forzosas extraordinarias. Obtienen nacionalización residiendo dos años continuos en la Nación; pero la autoridad puede acortar este término a favor del que lo solicite, alegando y probando servicios a la República.

Sobre este mandato, la Ley $\mathrm{N}^{\mathrm{o}} 346$ de Ciudadanía ${ }^{34}$ reconoce dos medios generales para adquirirla: ser argentino nativo o por opción (que es el caso de los hijos de argentinos nativos nacidos en un país extranjero que opten por la ciudadanía de origen); o ser ciudadano por naturalización (extranjeros mayores de 18 años, que residan en la República Argentina dos años continuos y manifiesten ante los jueces federales de sección su voluntad de hacerse ciudadano argentino) (art. 2).

Asimismo, el artículo $37^{35}$ de la $\mathrm{CN}$-incorporado en la reforma constitucional de 1994- contempla una serie de derechos, cada uno de ellos con sustantividad propia, pero que pueden englobarse en el genérico enunciado derechos políticos (tanto en su faz activa como pasiva) en estrecha conexión con otros derechos, como podrían ser el de reunión y participación, o bien el de participación política. ${ }^{36}$

A partir de estas precisiones, y en lo que respecta al ejercicio de los derechos políticos en el ámbito nacional, el Código

\footnotetext{
34 Sancionada el 1 de octubre de 1869 y modificada por la Ley No 26774 (BO: 2/11/2012).

35 “Esta Constitución garantiza el pleno ejercicio de los derechos políticos, con arreglo al principio de la soberanía popular y de las leyes que se dicten en consecuencia. El sufragio es universal, igual, secreto y obligatorio. La igualdad real de oportunidades entre varones y mujeres para el acceso a cargos electivos y partidarios se garantizará por acciones positivas en la regulación de los partidos políticos y en el régimen electoral".

36 Dalla Via, A. R., "La participación política y la reforma electoral en Argentina”, en Revista Justicia Electoral, Vol. 1, № 7, México, 2011, p. 89. Véase también, Ferreyra, R. G., op. cit., p. 528.
} 
Electoral Nacional reserva a los ciudadanos tanto la capacidad electoral activa como la pasiva. Así, en cuanto a la primera, el artículo 1 dispone que son electores los argentinos nativos y por opción, desde los 16 años de edad, ${ }^{37}$ y los argentinos naturalizados, desde los 18 años, que no tengan ninguna de las inhabilitaciones previstas por el Código.

Para la capacidad electoral pasiva en la elección de autoridades nacionales, la CN establece la exigencia de la ciudadanía; para ser diputado nacional se requiere haber cumplido la edad de veinticinco años y tener cuatro años de ciudadanía en ejercicio (art. 48); para ser elegido senador, haber sido seis años ciudadano de la Nación (art. 55); y para ser elegido presidente o vicepresidente de la Nación, el artículo 89 requiere haber nacido en el territorio argentino o, habiendo nacido en un país extranjero, ser hijo de ciudadano nativo, y las demás calidades exigidas para ser elegido senador.

Es decir que, además de los derechos otorgados a los extranjeros en el artículo 20 de la $\mathrm{CN}$, si un extranjero decide naturalizarse, puede ser, con cuatro años de ciudadanía, diputado nacional; con seis años de ciudadanía, senador nacional; y, gracias a la opción por la patria originaria, siendo hijo de ciudadano nativo, aunque haya nacido en el extranjero, puede ser presidente o vicepresidente de la República. ${ }^{38}$

Empero, el escenario que se presenta en el ámbito de las elecciones provinciales y municipales es diferente, ya que se otorga el derecho de sufragio de los extranjeros. De conformidad con la forma federal del Estado argentino, la delimitación de las competencias de las provincias en materia electoral se encuentra en el artículo 122 de la $\mathrm{CN}$, que establece la facultad de darse sus propias instituciones locales y elegir

\footnotetext{
37 El 31 de octubre de 2012, se sancionó la Ley 26774 que modificó de la siguiente manera el artículo 7 de la Ley $N^{0} 346$ de Ciudadanía: "Los argentinos que hubiesen cumplido la edad de 16 años, gozan de todos los derechos políticos conforme a la Constitución y a las leyes de la República".

38 Véase González, J. V., op. cit., p. 228.
} 
a sus gobernadores, legisladores y demás funcionarios, sin intervención del gobierno federal. En igual sentido, en la Ciudad Autónoma de Buenos Aires (CABA), el artículo 129 dispone que "La Ciudad de Buenos Aires tendrá un régimen de Gobierno autónomo con facultades propias de legislación y jurisdicción...".

Las constituciones de las provincias ${ }^{39}$ y de la CABA reconocen y garantizan a los extranjeros todos los derechos establecidos por la $\mathrm{CN}$ y, además, "... en uso de su soberanía política local, les han concedido otras prerrogativas que importan darles participación en las funciones del gobierno en determinada medida" ${ }^{40}$.

Continuando con la mención de los países que otorgan derechos de participación política a los extranjeros a nivel local, la Constitución Política de Colombia de 1991 establece en primer lugar que "La calidad de ciudadano en ejercicio es condición previa e indispensable para ejercer el derecho de sufragio, para ser elegido y para desempeñar cargos públicos que lleven anexa autoridad o jurisdicción" (art. 99). Sin embargo, a continuación, dispone que "La ley podrá conceder a los extranjeros residentes en Colombia el derecho al voto en las elecciones y consultas populares de carácter municipal o distrital" (art. 100).

Venezuela y Bolivia limitan el sufragio activo de los extranjeros a los procesos electorales municipales. En el primer caso, se exige una residencia de más de diez años en el país (art. 64 de la Constitución). En el segundo, para ser elector se dispone que el extranjero tenga que residir legalmente al menos dos años en el municipio (art. 45 de la Ley del Régimen Electoral).

Paraguay y Perú autorizan el derecho de sufragio activo y pasivo de los extranjeros en las elecciones municipales. En el primer caso, el artículo 120 de la Constitución establece:

39 Excepto la Constitución de la provincia de Formosa.

40 Véase González, J. V., op. cit., p. 229. 
Son electores los ciudadanos paraguayos radicados en el territorio nacional, sin distinción, que hayan cumplido diez y ocho años.

Los ciudadanos son electores y elegibles, sin más restricciones que las establecidas en esta Constitución y en la ley. Los extranjeros con radicación definitiva tendrán los mismos derechos en las elecciones municipales.

En Perú, la Ley de Elecciones Municipales $\mathrm{N}^{\mathrm{o}} 26864,{ }^{41}$ dispone en el artículo 7:

Los extranjeros mayores de 18 años, residentes por más de dos años continuos previos a la elección, están facultados para elegir y ser elegidos, excepto en las municipalidades de frontera, siempre y cuando estén debidamente inscritos en el registro correspondiente. Para ejercer este derecho, el extranjero se identifica con su respectivo carné de extranjería.

La Constitución de la República de Ecuador de 2008, en el artículo 63, otorga el derecho de sufragio activo a los extranjeros en todos los procesos electorales, siempre que hayan residido legalmente en el país al menos cinco años. Asimismo, el Código de la Democracia ${ }^{42}$ se refiere a los derechos políticos de los extranjeros y establece que el voto será facultativo para las extranjeras y extranjeros desde los 16 años de edad que hayan residido legalmente en el país al menos cinco años y se hubieren inscrito en el Registro Electoral.

\footnotetext{
41 Publicada el 14 de octubre de 1997.

42 Ley Orgánica Electoral y de Organizaciones Políticas de la República de Ecuador, dada por Ley N² 2, publicada en Registro Oficial Suplemento 578 de 27 de abril del 2009: “Art. 2.: En el ámbito de esta ley las ecuatorianas y ecuatorianos gozan de los siguientes derechos: 1. Elegir y ser elegidos; 2. Participar en los asuntos de interés público; 3. Presentar proyectos de iniciativa popular normativa; 4. Ser consultados; 5 . Revocar el mandato que hayan conferido a las autoridades de elección popular; 6. Conformar partidos y movimientos políticos, afiliarse o desafiliarse libremente de ellos y participar en todas las decisiones que éstos adopten; 7. Intervenir como veedores u observadores en los procesos electorales; de conformidad a lo establecido en esta Ley y su Reglamento; y, 8. Exigir la rendición de cuentas y la transparencia de la información de los sujetos políticos. Las personas extranjeras gozarán de estos derechos en los términos previstos en esta ley".
} 
Similar regulación se observa en el artículo 14 de la Constitución Política de Chile, al disponer que los extranjeros avecindados en el país por más de cinco años podrán ejercer el derecho de sufragio en los casos y formas que determine la ley. En este sentido, la Ley Orgánica Constitucional sobre Votaciones Populares y Escrutinios $\mathrm{N}^{\circ} 18100^{43}$ considera electores " $\mathrm{a}$ los ciudadanos con derecho a sufragio y extranjeros que figuren en los Padrones de Mesa y que tengan cumplidos dieciocho años de edad el día de la votación" (art. 60).

En Uruguay, el artículo 78 del texto constitucional otorga el derecho al sufragio, sin necesidad de obtener previamente ciudadanía legal, a los hombres y a las mujeres extranjeros, de buena conducta, con familia constituida en el país y que, poseyendo algún capital en giro o propiedad en el país o profesando alguna ciencia, arte o industria, tengan residencia habitual de, por lo menos, quince años.

\section{IV.4. Países que reservan el derecho de sufragio a los nacionales en todo tipo de elecciones}

De conformidad con lo dispuesto en el artículo 34 de la Constitución de México, son ciudadanos mexicanos los varones y mujeres que, teniendo la nacionalidad mexicana, ya sea por nacimiento o por naturalización, hayan cumplido 18 años y tengan un modo honesto de vivir. Por exclusión, los extranjeros, es decir, los individuos que no tienen la nacionalidad mexicana y por tanto no poseen ciudadanía, carecen también de los derechos políticos ${ }^{44}$. Al mismo tiempo, se prohíbe a los extranjeros "inmiscuirse en los asuntos políticos del país" (art. 33 del texto constitucional).

Del mismo modo, la Constitución de la República Federativa de Brasil niega derechos políticos a los extranjeros, ya que el artículo 14 expresa que "no pueden alistarse como electores

\footnotetext{
43 Publicada el 6 de mayo de 1988.

44 Véase Fix-Fierro, H., Los derechos políticos de los mexicanos, México, Universidad Nacional Autónoma de México, 2006, p. 36.
} 
los extranjeros". No obstante, la excepción se lee en el artículo 12, que establece que a los portugueses con residencia permanente en el país les serán atribuidos los derechos inherentes al brasileño de origen.

La reserva a los nacionales del derecho de sufragio en todo tipo de elecciones también se presenta en Costa Rica ${ }^{45}$, El Salvador $^{46}$, Guatemala, Honduras, Nicaragua, Panamá, República Dominicana y Cuba. ${ }^{47}$

\section{Regímenes de extranjería en los países que conforman el Mercosur ${ }^{48}$}

Del análisis efectuado en el apartado anterior, se observa que la Argentina, Paraguay, Uruguay, Venezuela ${ }^{49}$ y Bolivia $^{50}$ admiten el derecho de sufragio de los extranjeros, aunque con notables diferencias. Brasil es el único Estado Parte del Mercosur

45 La Constitución política de la República de Costa Rica dispone en el art. 19 que "Los extranjeros tienen los mismos deberes y derechos individuales y sociales que los costarricenses, con las excepciones y limitaciones que esta Constitución y las leyes establecen. No pueden intervenir en los asuntos políticos del país, y están sometidos a la jurisdicción de los tribunales de justicia y de las autoridades de la República, sin que puedan ocurrir a la vía diplomática, salvo lo que dispongan los convenios internacionales".

46 La Constitución de la República de El Salvador establece que son ciudadanos todos los salvadoreños mayores de dieciocho años (art. 71); los derechos políticos del ciudadano son $1^{0}$ ejercer el sufragio; $2^{\circ}$ asociarse para constituir partidos políticos de acuerdo con la ley e ingresar a los ya constituidos; y, $3^{\circ}$ optar a cargos públicos, cumpliendo con los requisitos que determina la Constitución y las leyes secundarias (art. 72). Asimismo, el art. 97 dispone que "Los extranjeros que directa o indirectamente participen en la política interna del país pierden el derecho a residir en él".

47 Art. 131 de la Constitución de la República de Cuba y arts. 6 y 8 de la Ley Electoral N 72 sancionada el 29 de octubre de 1992.

48 Ver Anexo I.

49 La República Bolivariana de Venezuela se encuentra suspendida en todos los derechos y obligaciones inherentes a su condición de Estado Parte del Mercosur, de conformidad con lo dispuesto en el segundo párrafo del artículo $5^{\circ}$ del Protocolo de Ushuaia de fecha 24 de julio de 1998.

50 El Protocolo de Adhesión de Bolivia al Mercosur ya fue firmado por la totalidad de los Estados Partes en 2015 y ahora se encuentra en vías de incorporación por los congresos de los Estados Partes. 
que reserva el derecho de sufragio a los nacionales en todo tipo de elecciones. A continuación, analizamos caso por caso.

\section{V.1. Marco normativo argentino de participación} de los extranjeros en las elecciones locales

En la Argentina, como la materia electoral constituye una competencia reservada a cada una de las provincias en la medida en que no fue expresamente delegada a la Nación, se observa una variedad de sistemas electorales, y al mismo tiempo diferentes disposiciones y requisitos respecto de las posibilidades de participación política de los extranjeros y extranjeras en los veintitrés distritos electorales. De la comparación de las notas principales de los derechos políticos de los extranjeros en las provincias y en la CABA resulta lo siguiente: ${ }^{51}$

a) La única provincia que le reserva el derecho de sufragio, en todos los niveles, a los nacionales, es Formosa. El resto de las provincias y la CABA admiten la participación plena de los extranjeros en las funciones electivas y deliberantes del régimen provincial y municipal, según el caso.

b) Algunas provincias habilitan a los extranjeros para votar cargos provinciales y municipales (Buenos Aires, Córdoba, La Rioja y Tucumán) y la mayoría los autoriza para los cargos municipales y comunales (Catamarca, Corrientes, Chaco, Chubut, Entre Ríos, Jujuy, La Pampa, Mendoza, Misiones, Neuquén, Río Negro, Salta, Santa Cruz, Santa Fe, San Juan, San Luis, Santiago del Estero y Tierra del Fuego). Por su parte, en la CABA se permite a los extranjeros votar los cargos de jefe y vicejefe de gobierno, diputados e integrantes de las Juntas Comunales.

c) En todos los casos, la calidad de elector se prueba, a los fines del sufragio, exclusivamente por su inclusión voluntaria en el Registro Electoral de los Extranjeros o en el Registro Electoral de cada Municipio o de la CABA.

51 Un análisis más detallado puede verse en Perícola, M. A., "El derecho de sufragio de los extranjeros", en Revista Pensar en Derecho, Nº 7, Año 4, Buenos Aires, Eudeba, 2015, pp. 167-198. 
d) Las condiciones solicitadas para poder ingresar en el Registro de Electores de Extranjeros presentan diferencias en cada provincia y en la CABA, sobre todo, respecto de la cantidad de años de residencia requeridos. Para el caso de elecciones provinciales, se requieren dos años de residencia en Buenos Aires, La Rioja y Tucumán y cinco en Córdoba. En las elecciones municipales, un año de residencia en Santa Cruz y San Luis; dos años en Buenos Aires, Córdoba, Corrientes, Chaco, Entre Ríos, Jujuy, La Rioja, Mendoza, Neuquén, Salta, Santa Fe, San Juan, Santiago del Estero y Tucumán; tres años en Chubut, Misiones y Río Negro; cuatro años en Catamarca; cinco años en la ciudad de Ushuaia (e igual cantidad de tiempo como contribuyentes municipales) o diez años de domicilio real para quienes no sean contribuyentes y acrediten buena conducta; diez años en el municipio de Río Grande; seis años en La Pampa; y, para el caso de las elecciones en la CABA, se requiere que los extranjeros acrediten tres años de residencia.

e) Además, en algunos ordenamientos se estipulan otros requisitos aparte de los años de residencia en el ámbito municipal y comunal, como estar casado con ciudadano argentino, ser contribuyente o ejercer actividad lícita (Córdoba, Chubut, Misiones, Neuquén, Santa Cruz, Santa Fe y Tucumán).

f) En las regulaciones en que se acepta el derecho de sufragio pasivo de los extranjeros, se circunscribe únicamente al ámbito municipal. $\mathrm{Al}$ respecto, se dispone una cantidad mínima de años de residencia según el caso: un año en Santa Cruz, dos años en Mendoza, cuatro años en Santa Fe y cinco años en Buenos Aires, Córdoba, Corrientes, Chubut, Neuquén, San Juan y Tucumán. Asimismo, suelen establecerse límites a la cantidad de concejales extranjeros. No pueden exceder la tercera parte del número total de miembros en el Concejo Deliberante en Buenos Aires, Corrientes y Chubut; no puede haber más de dos extranjeros en cada Concejo Deliberante en La Rioja y Mendoza; y no puede haber un número mayor de la mitad del total de los miembros en Santa Cruz. 
g) Respecto a la obligatoriedad del voto de los extranjeros, las regulaciones de las provincias de Buenos Aires, Mendoza, Neuquén y la CABA establecen que, si el extranjero se empadrona una vez, el voto pasa a ser obligatorio en las elecciones siguientes.

h) Río Negro y Tucumán permiten la afiliación de los extranjeros a las agrupaciones políticas municipales y su acceso a cargos partidarios locales.

i) Las constituciones provinciales de Buenos Aires, La Rioja y Salta, además, habilitan a los extranjeros para intervenir como votantes en la consulta popular. Buenos Aires, La Rioja y Tucumán, los habilitan para participar de las elecciones para Convencionales Constituyentes.

\section{V.2. El derecho de sufragio activo y pasivo en las elecciones municipales de Paraguay}

La República de Paraguay equipara a los ciudadanos paraguayos electores y elegibles con los extranjeros con radicación definitiva para el caso de las elecciones municipales. La Ley No 978/96 de Migraciones establece en el artículo 21:

Los extranjeros que obtengan su radicación definitiva en el país como "residentes permanentes" gozarán de los mismos derechos y tendrán las mismas obligaciones que los paraguayos, con las modalidades y las limitaciones establecidas por la Constitución Nacional y las leyes. El otorgamiento de la residencia permanente podrá hacerse extensivo al cónyuge, hijos menores y padres extranjeros de la persona admitida e incluida en el artículo 14 incisos 1) 2) y 3).

Para acceder a la residencia definitiva otorgada a ciudadanos extranjeros de cualquier nacionalidad que deseen establecerse en el territorio paraguayo en calidad de residentes permanentes, entre los requisitos que establece la Ley $N^{\circ}$ 978/96 se encuentran los siguientes: residencia de al menos 5 años en el país, certificado de antecedentes penales, certificado sanitario, 
constancia de estado civil (si corresponde) y demostración de solvencia económica.

El Código Electoral Paraguayo (CEP) aprobado por Ley $\mathrm{N}^{\mathrm{o}} 834 / 96^{52}$, reglamentario del artículo 120 de la Constitución Nacional, dispone, con relación al derecho de sufragio activo, que son electores los ciudadanos paraguayos radicados en el territorio nacional y los extranjeros con radicación definitiva que hayan cumplido dieciocho años de edad, que reúnan los requisitos exigidos por la ley y que estén inscriptos en el Registro Cívico Permanente (art. 2).

El derecho de sufragio pasivo se otorga a los ciudadanos paraguayos, desde los dieciocho años de edad, que no se encuentren incursos en las causales de inelegibilidad establecidas en la Constitución Nacional y las leyes. Igualmente lo son los ciudadanos naturalizados, aunque con las limitaciones establecidas en la Constitución Nacional. Los extranjeros residentes en el país son elegibles para funciones municipales (art. 95 CEP).

Por su parte, la elección de las Juntas Municipales está regulada por la Ley Orgánica Municipal No 3966. ${ }^{53}$ Para ser intendente, se requiere ser ciudadano paraguayo, mayor de veinticinco años de edad, natural del municipio o con una residencia en él de por lo menos cinco años. Para ser concejal, se requiere ser ciudadano paraguayo, mayor de veintitrés años de edad, natural del municipio o con una residencia en él de por lo menos tres años. Los extranjeros con radicación definitiva tendrán los mismos derechos que los ciudadanos paraguayos (art. 22).

Para ser electo diputado, senador y presidente o vicepresidente se requiere la nacionalidad paraguaya natural (arts. 221, 223 y 228 de la Constitución). Los extranjeros nacionalizados por naturalización ${ }^{54}$ no pueden postularse para ocupar cargos públicos electivos.

\footnotetext{
52 Con las modificaciones posteriores de las Leyes $N^{0} 5286,5350$ y 5376.

53 Fecha de publicación: 10/2/2010.

54 Para obtener la nacionalidad paraguaya por naturalización, se requiere mayoría de edad, radicación mínima de tres años en territorio nacional, ejercicio en el país de alguna profesión, oficio, ciencia, arte o industria, y buena conducta (art. 148 de la Constitución).
} 


\section{V.3. El derecho de sufragio activo en todo tipo de elecciones en Uruguay}

En la República Oriental del Uruguay, el artículo 78 de la Constitución otorga el derecho al sufragio activo, sin necesidad de obtener previamente ciudadanía legal, a los hombres y a las mujeres extranjeros que tengan residencia habitual de, por lo menos, quince años. La residencia se prueba en instrumento público o privado, y si la justificación fuera satisfactoria para la autoridad encargada de juzgarla, el extranjero quedará habilitado para el ejercicio del voto desde que se inscriba en el Registro Cívico.

La Ley de Elecciones $\mathrm{N}^{\circ} 7812$ del 16 de enero de 1925 (modificada por la Ley $\mathrm{N}^{\circ} 17113$ del 9 de junio de 1999 y por Ley $\mathrm{N}^{\circ} 17239$ del 2 de mayo de 2000) dispone en el artículo $1^{\circ}$ que son electores "todas las personas" 55 inscriptas en el Registro Cívico Nacional que por resolución ejecutoriada de la Corte estén comprendidos en el momento de la elección en la sección "habilitados para votar" y que se encuentren inscriptos en el Registro Cívico Nacional. Se observa entonces que se incorpora una categoría especial de "electores no ciudadanos": los extranjeros con residencia habitual de al menos quince años en Uruguay que se inscriban en el Registro Cívico Nacional.

El derecho de sufragio pasivo se reserva a los ciudadanos naturales y a los ciudadanos legales. Para ser representante se requiere ciudadanía legal con cinco años de ejercicio; para ser senador, ciudadanía legal con siete años de ejercicio; y para ser elegido presidente y vicepresidente de la República sólo se permite la ciudadanía natural.

\footnotetext{
55 El nuevo texto de 1999 sustituyó el vocablo "ciudadanos" que utilizaba la ley de 1925 por el de "personas", en razón de que a partir de la reforma constitucional de 1934, también integran el Registro Cívico Nacional y son, por tanto, electores, los extranjeros no ciudadanos que han obtenido certificado de residencia al amparo del art. 78 de la Constitución.
} 


\section{V.4. El derecho al voto de los extranjeros para las elecciones parroquiales, municipales y estadales en Venezuela}

Venezuela permite el sufragio activo de los extranjeros que tengan más de diez años de residencia en el país, en los procesos electorales parroquiales, municipales y estadales (art. $64 \mathrm{de}$ la Constitución).

La Ley Orgánica de Procesos Electorales ${ }^{56}$ regula la inscripción de los extranjeros y las extranjeras mayores de dieciocho años de edad, con más de diez años de residencia en el país en el Registro Electoral (art. 29). Respecto del ejercicio del derecho de sufragio activo, el artículo 41 los autoriza a ejercer su derecho al voto en los procesos electorales para elegir a los o las titulares de los cargos de elección popular a nivel regional o municipal.

Al mismo tiempo, la Ley Orgánica de Sufragio y Participación Política ${ }^{57}$ regula el derecho a voto de los extranjeros en las elecciones Municipales y Parroquiales que correspondan a su lugar de residencia, en las mismas condiciones establecidas para los venezolanos (art. 86) y en el artículo 98 tercer párrafo se especifica que los extranjeros que cumplan con los requisitos establecidos en la Constitución deberán acudir al Centro de Actualización que corresponda a su Vecindad Electoral a fin de solicitar su inscripción en el Registro Electoral.

De conformidad con lo regulado en el artículo 41 de la Constitución de la República Bolivariana de Venezuela, sólo los venezolanos y venezolanas por nacimiento y sin otra nacionalidad podrán ejercer los cargos de presidente o presidenta de la República y vicepresidente ejecutivo o vicepresidenta ejecutiva. En cambio, para ejercer los cargos de diputado o diputada a la Asamblea Nacional, ministro o ministra, gobernadores o gobernadoras y alcaldes o alcaldesas de Estados y Municipios no

\footnotetext{
56 Gaceta Oficial № 5928 E del 12/8/2009.

57 Gaceta Oficial № 5200 del 30/12/1997.
} 
fronterizos, los venezolanos y venezolanas por naturalización deben tener domicilio con residencia ininterrumpida en Venezuela no menor de quince años.

\section{V.5. La participación política de los extranjeros en Bolivia}

El apartado II del artículo 27 de la Constitución Política del Estado de Bolivia dispone que las extranjeras y los extranjeros residentes en Bolivia tienen derecho a sufragar en las elecciones municipales. Por su parte, la Ley No 26 del Régimen Electoral del 30 de junio de 2010 otorga el derecho de sufragio activo a los extranjeros en procesos electorales municipales, cuando residan legalmente al menos dos (2) años en el municipio. Para ser electora o elector, es condición indispensable estar registrada o registrado en el padrón electoral y habilitada o habilitado para votar (art. 45).

Para ser candidata o candidato a presidente/vicepresidente y a la Asamblea Legislativa Plurinacional, se requiere cumplir con las condiciones generales de acceso al servicio público estipuladas en el artículo 234 de la Constitución:

1. Contar con la nacionalidad boliviana; 2. Ser mayor de edad; 3. Haber cumplido con los deberes militares; 4. No tener pliego de cargo ejecutoriado, ni sentencia condenatoria ejecutoriada en materia penal, pendientes de cumplimiento; 5 . No estar comprendida ni comprendido en los casos de prohibición y de incompatibilidad establecidos en la Constitución; 6. Estar inscripta o inscripto en el padrón electoral; 7. Hablar al menos dos idiomas oficiales del país.

Además, para ser candidata o candidato a la Asamblea Legislativa Plurinacional, se solicita haber residido de forma permanente al menos los dos años inmediatamente anteriores a la elección en la circunscripción correspondiente (art. 149). 


\section{V.6. Brasil: La reserva a los nacionales de los derechos políticos en todo tipo de elecciones y el estatuto preferencial de los portugueses}

Si bien el artículo 5 de la Constitución de la República Federativa de Brasil dispone que todos son iguales ante la ley, sin distinción de cualquier naturaleza, garantizando a los brasileños y a los extranjeros residentes en el país la inviolabilidad del derecho a la vida, a la libertad, a la igualdad, a la seguridad y a la prioridad; el artículo 14 , apartado $2^{\circ}$, niega derechos políticos a los extranjeros: "No pueden alistarse como electores los extranjeros y, durante el período del servicio militar, los reclutados" 58 .

La situación jurídica del extranjero en Brasil ha estado regulada hasta mayo de 2017 por la Ley No 6815, del 19 de agosto de 1980. En lo concerniente a los derechos de participación política, estaba especialmente vedado el ejercicio de cualquier actividad de naturaleza política (art. 107). La nueva Ley de Migración $\mathrm{N}^{\mathrm{0}} 13445$, sancionada ${ }^{59}$ por el presidente Michel Temer el 24 de mayo de $2017^{60}$ quita la prohibición y garantiza a los inmigrantes el derecho de reunión con fines pacíficos y el derecho de asociación, inclusive sindical, para fines lícitos, aunque el derecho de sufragio se mantiene reservado a los nacionales.

Respecto de la nacionalidad, el artículo 12 de la Constitución distingue entre "brasileños de origen" y "brasileños naturalizados". Sin embargo, atento a los altos valores históricos morales, culturales, lingüísticos y étnicos que unen a los pueblos brasileños y portugueses, en el apartado $1^{\circ}$ se efectúa una excepción en el régimen de extranjería: "A los portugueses con residencia permanente en el país les serán atribuidos los derechos inherentes al brasileño de origen, si hubiese reciprocidad en favor de los brasileños, salvo en los casos previstos en esta Constitución".

\footnotetext{
58 Véase también el art. 5 del Código Electoral (Ley № 4737 del 15/7/1965).

59 Con 18 vetos.

60 Diario Oficial de la Unión, 25/5/2017.
} 
La cuestión se encuentra reglamentada por el Tratado de Amistad, Cooperación y Consulta, firmado por Portugal y Brasil en Puerto Seguro el 22 de abril de $2000{ }^{61}$ Entre los artículos 12 y 22 se regula la parte pertinente al "Estatuto de igualdad entre portugueses y brasileños" 62 .

Con relación a los derechos políticos, el artículo 17 establece lo siguiente:

1. El goce de derechos políticos por portugueses en Brasil y por brasileños en Portugal sólo será reconocido a los que tengan tres años de residencia habitual y depende de requerimiento a la autoridad competente.

2. La igualdad en cuanto a los derechos políticos no cubre a las personas que, en el Estado de la nacionalidad, hayan sido privadas de derechos equivalentes.

3. El goce de los derechos políticos en el Estado de residencia implica la suspensión del ejercicio de los mismos derechos en el Estado de la nacionalidad.

Además, el apartado $2^{\circ}$ del artículo 12 del texto constitucional dispone que la ley no podrá establecer distinción entre brasileños de origen y naturalizados, salvo en los casos previstos en la Constitución. A continuación, el apartado $3^{\circ}$ menciona los cargos que son privativos del brasileño de origen (presidente y vicepresidente de la República; presidente de la Cámara de Diputados; presidente del Senado Federal; ministro del Supremo Tribunal Federal; de la carrera diplomática; de oficial de las Fuerzas Armadas).

\section{El Estatuto de la Ciudadanía del Mercosur}

El Consejo del Mercado Común (CMC) estableció un plan de acción para la conformación progresiva de un Estatuto de la

\footnotetext{
61 El Tratado revocó la Convención sobre Igualdad de Derechos y Deberes, promulgada por el Decreto $N^{0}$ 70.436, del 18 de abril de 1972.

62 El reconocimiento de la igualdad por brasileros en Portugal y por portugueses en Brasil no implica la pérdida de las respectivas nacionalidades.
} 
Ciudadanía del Mercosur a través de la Decisión 064/2010 ${ }^{63}$. El Estatuto estará integrado por un conjunto de derechos fundamentales y beneficios para los nacionales de los Estados Partes del Mercosur. A tal fin, se indican once sectores que conformarán el Plan de Acción:

1. Circulación de personas

2. Fronteras

3. Identificación

4. Documentación y cooperación consular

5. Trabajo y Empleo

6. Previsión social

7. Educación

8. Transporte

9. Comunicaciones

10. Defensa del consumidor

11. Derechos políticos

Con relación a los derechos políticos ${ }^{64}$, se propone lo siguiente:

Evaluar las condiciones para avanzar progresivamente en el establecimiento de derechos políticos, de acuerdo con las legislaciones nacionales que reglamenten su ejercicio, en favor de los ciudadanos de un Estado Parte del Mercosur que residan en otro Estado Parte del que no sean nacionales, incluyendo la posibilidad de elegir parlamentarios del Mercosur.

Asimismo, en el artículo 7 se dispone que el Plan de Acción deberá estar íntegramente implementado en el $30^{\circ}$ aniversario del Mercosur y que el Estatuto de la Ciudadanía del Mercosur podrá ser instrumentado mediante la firma de un protocolo

\footnotetext{
63 Foz de Iguazú, 16/12/2010.

64 El ámbito encargado de esta política será la Reunión de Ministros de Justicia Reunión de Ministros del Interior.
} 
internacional que incorpore el concepto de "Ciudadano del Mercosur" y forme parte del Tratado de Asunción.

Teniendo en cuenta los regímenes de extranjería de los países que conforman el Mercosur, el establecimiento de derechos políticos en favor de los ciudadanos de un Estado Parte del Mercorsur que residan en otro Estado Parte del que no sean nacionales requiere una significante adecuación de las legislaciones nacionales ${ }^{65}$. Ello así, por ejemplo, si se decidiera incorporar el concepto de "ciudadano del Mercosur", considerando la experiencia de la Unión Europea que, a partir de la instauración de la ciudadanía europea, otorga a todo ciudadano que resida en un Estado miembro del que no es nacional el derecho de sufragio activo y pasivo en las elecciones municipales y en las del Parlamento Europeo. El mapa de la participación política de los extranjeros en el Mercosur nos señala los desafíos para llevar a cabo la implementación de la "ciudadanía del Mercosur" a través del derecho de sufragio activo y pasivo en las elecciones locales y en el Parlamento del Mercosur ${ }^{66}$.

En la Argentina las adecuaciones legislativas en el nivel provincial y de la CABA que tendrían que realizarse para el caso de las elecciones municipales o locales son las siguientes:

65 Tal como aconteció en España con la reforma del artículo 13.2 de la Constitución en 1992, que actualmente prevé la posibilidad de extender a los extranjeros el derecho de sufragio, tanto activo como pasivo, en las elecciones municipales y la inserción de un título especial en la LOREG para las elecciones al Parlamento Europeo (arts. 210 y 210 bis).

66 El Parlamento del Mercosur fue constituido el 14 de diciembre 2006, como sustituto de la Comisión Parlamentaria Conjunta, y es el órgano, por excelencia, representativo de los intereses de los ciudadanos de los Estados Partes.

En el 2009, se celebró el Acuerdo Político que estableció normas para que los Estados Partes sean representados, a partir de las elecciones directas, de acuerdo con el criterio de proporcionalidad atenuada. A partir de sus respectivas elecciones directas, el organismo tendrá la siguiente composición parlamentaria: Argentina, 43; Brasil, 75; Paraguay, 18; Uruguay, 18 y Venezuela, 33.

Con la Decisión que establece a Bolivia como Estado en proceso de adhesión al Mercosur, este país pasa a integrar el Parlasur con derecho a voz y participación, sin derecho a voto. En el momento que se complete la adhesión plena de Bolivia al Mercosur, el país pasará a tener 18 Parlamentarios en el Parlasur. 
1) la regulación del derecho de sufragio tanto en la faz activa como pasiva en Formosa para establecer, al menos, los derechos políticos a favor de los ciudadanos de los Estados Partes del Mercosur que residan en la provincia; 2) la unificación del requisito de la residencia de los ciudadanos de los Estados Partes del Mercosur en todas las legislaciones; 3) reformar las normas que en trece distritos electorales no permiten el derecho de sufragio pasivo de los extranjeros en las elecciones municipales (Catamarca, Chaco, Entre Ríos, Jujuy, La Pampa, La Rioja, Misiones, Río Negro, Salta, San Luis, Santiago del Estero, Tierra del Fuego y CABA). Para las elecciones del Parlamento del Mercosur, la extensión del derecho de sufragio activo a los extranjeros depende única y exclusivamente de la legislación nacional, ya que el artículo 37 de la Constitución Nacional garantiza el pleno ejercicio de los derechos políticos sin observarse reserva alguna a los nacionales. Por el contrario, la extensión del derecho de sufragio pasivo no sería plausible mediante una reforma legislativa, sino que requeriría una reforma constitucional: los candidatos a parlamentarios del Mercosur deben cumplir con los requisitos exigibles para ser diputado nacional (art. $11 \mathrm{del}$ Protocolo Constitutivo del Parlamento del Mercosur).

La Constitución de Uruguay otorga el derecho al sufragio activo, sin necesidad de obtener previamente ciudadanía legal, a los hombres y a las mujeres extranjeros que tengan residencia habitual de, por lo menos, quince años. Por ello, tanto para las elecciones municipales como para el Parlamento del Mercosur, será necesaria una reforma constitucional que permita el ejercicio de los derechos políticos en la faz pasiva a favor de los ciudadanos de los Estados Partes del Mercosur y eliminar el requisito de la residencia.

La Constitución de Paraguay equipara a los ciudadanos paraguayos electores y elegibles con los extranjeros con radicación definitiva para el caso de las elecciones municipales. La implementación de la ciudadanía del Mercosur en el marco municipal exige una reforma constitucional que excluya el requisito de la radicación definitiva. Para el caso de las 
elecciones del Parlamento del Mercosur también se requiere una reforma del texto constitucional que otorgue derechos políticos tanto en la faz activa como pasiva, ya que el artículo 246 del Código Electoral dispone que son elegibles para desempeñarse como senadores, diputados y parlamentarios del Mercosur, los que "hallándose en ejercicio de su derecho de sufragio pasivo reúnan las condiciones establecidas en la Constitución Nacional y no se hallen comprendidos en las inhabilidades establecidas en la misma".

Venezuela permite el sufragio activo de los extranjeros que tengan más de diez años de residencia en el país, en los procesos electorales parroquiales, municipales y estadales (art. 64 de la Constitución). La reforma constitucional ha de suprimir el requisito de la residencia en favor de los ciudadanos de los Estados Partes del Mercosur para las elecciones locales y otorgarles el derecho a ser elegidos; respecto del Parlamento del Mercosur, la reforma tiene que otorgar en pleno los derechos políticos.

En Bolivia, en el marco de las elecciones municipales, la adecuación normativa debería efectuarse en el artículo 45 de la Ley $\mathrm{N}^{\circ} 26$ del Régimen Electoral, prescindiendo del requisito de residencia de dos años y agregando el derecho de sufragio pasivo para los ciudadanos de los Estados Partes del Mercosur. Para las elecciones del Parlamento del Mercosur tendría que reformarse la Constitución, atento a las condiciones generales de acceso al servicio público estipuladas en el artículo 234.

En Brasil, tanto para las elecciones locales como para las elecciones del Parlamento del Mercosur será necesario avanzar con una propuesta de enmienda constitucional que otorgue derechos políticos a los ciudadanos de los Estados Partes del Mercosur.

\section{Conclusiones}

La situación en los Estados miembros de la Unión Europea presenta un notorio progreso con relación a los derechos políticos de los extranjeros, al definir una ciudadanía europea que les 
reconoce capacidad electoral activa y pasiva para las elecciones municipales y del Parlamento Europeo. No obstante, al margen de esta característica común, varios Estados -entre los que se encuentran Alemania, Francia e Italia- reservan el derecho de sufragio a los nacionales $\mathrm{y}$, por consiguiente, no permiten la participación política de ciudadanos de terceros países. Asimismo, España y Portugal presentan un condicionamiento constitucional que exige reciprocidad.

El factor de la nacionalidad persiste como componente específico del derecho de sufragio. Respecto de la participación política para elegir autoridades nacionales, en veintitrés de los veintiséis países considerados, se reserva el derecho de sufragio a los nacionales; el mayor grado de apertura lo presentan Ecuador, Chile y Uruguay, al autorizar el derecho de sufragio activo para configurar todas las instancias representativas. Mientras que el derecho de sufragio activo de los extranjeros circunscripto a elecciones locales se permite en nueve países latinoamericanos -con una exigencia de residencia que oscila entre los dos y los quince años-, el derecho de sufragio en su faz pasiva se observa únicamente en los ordenamientos de la Argentina, ${ }^{67}$ Perú y Paraguay. Por ello, en la medida en que se deje atrás el dualismo ciudadanía-nacionalidad y se perfile una ciudadanía de residencia en los Estados Partes del Mercosur, podrá incorporarse el concepto "ciudadano del Mercosur" y los extranjeros podrán participar en la formación del gobierno representativo a través del ejercicio de sus derechos políticos. En pocas palabras, los desafíos que tienen por delante los Estados Partes para hacer realidad el ideal igualitario e incluyente que supone la ciudadanía del Mercosur pueden ser abarcados por uno solo: la "democratización de la ciudadanía"68.

\footnotetext{
67 En las provincias de Buenos Aires, Chubut, Córdoba, Corrientes, Mendoza, Neuquén, San Juan, Santa Cruz, Santa Fe y Tucumán.

68 Aláez Corral, B., "Los condicionamientos Constitucional-Democráticos de la Nacionalidad y la Ciudadanía", en Costa, P. y Aláez Corral, B., Nacionalidad y Ciudadanía, Madrid, Fundación Coloquio Jurídico Europeo, 2008, p. 91.
} 


\section{Anexo I. Cuadro comparativo}

El derecho de sufragio de los extranjeros en los Estados Partes del Mercosur

\begin{tabular}{|c|c|c|c|}
\hline \multirow[b]{2}{*}{ Países } & \multicolumn{2}{|c|}{ Sufragio activo } & \multirow{2}{*}{$\begin{array}{c}\text { Sufragio pasivo } \\
\text { Elecciones } \\
\text { municipales } \\
\text { (años de residencia) }\end{array}$} \\
\hline & $\begin{array}{l}\text { Elecciones } \\
\text { nacionales } \\
\text { (años de } \\
\text { residencia) }\end{array}$ & $\begin{array}{c}\text { Elecciones } \\
\text { municipales } \\
\text { (años de residencia) }\end{array}$ & \\
\hline Argentina & No & Sí (entre 2 y 10 años) & Sí (entre 1 y 5 años) ${ }^{(a)}$ \\
\hline Bolivia & No & Sí (2 años) & No \\
\hline Brasil & No & $\mathrm{No}^{(\mathrm{b})}$ & No \\
\hline Paraguay & No & $\begin{array}{l}\text { Sí (radicación } \\
\text { definitiva) }\end{array}$ & $\begin{array}{l}\text { Sí (radicación } \\
\text { definitiva) }\end{array}$ \\
\hline Uruguay & Sí (15 años) & Sí (15 años) & No \\
\hline Venezuela & No & Sí (10 años) & No \\
\hline
\end{tabular}

Fuente: Elaboración propia a partir de los datos aportados por las Constituciones y las leyes electorales de los países. 